\title{
Work-related asthma in the USA: nationally representative estimates with extended follow-up
}

\author{
James N Laditka, Sarah B Laditka (1) , Ahmed A Arif 주, Jessica N Hoyle
}

\begin{abstract}
- Additional material is
published online only. To view please visit the journal online (http://dx.doi.org/10.1136/ oemed-2019-106121).

Public Health Sciences, University of North Carolina at Charlotte, Charlotte, North Carolina, USA
\end{abstract}

\section{Correspondence to} Dr Sarah B Laditka, Public Health Sciences, University of North Carolina at Charlotte, Charlotte, NC 28223, USA; sladitka@uncc.edu

Received 30 July 2019 Revised 10 April 2020 Accepted 25 April 2020 Published Online First 13 May 2020

\section{Check for updates}

(C) Author(s) (or their employer(s)) 2020. No commercial re-use. See rights and permissions. Published by BMJ.

\footnotetext{
To cite: Laditka JN, Laditka SB, Arif AA, et al. Occup Environ Med 2020;77:617-622.
}

\begin{abstract}
Objective We studied the associations of working in occupations with high asthma trigger exposures with the prevalence and incidence of asthma, and with ever reporting an asthma diagnosis throughout working life. Methods We used the nationally representative Panel Study of Income Dynamics (1968-2015; n=13957; 205498 person-years), with annual reports of occupation and asthma diagnoses across 48 years. We compared asthma outcomes in occupations likely to have asthma trigger exposures with those in occupations with limited trigger exposures. We estimated the prevalence ratios and the incidence risk ratios using log-binomial regression adjusted for age, sex, race/ethnicity, education, and current and past atopy and smoking, and accounting for the survey design and sampling weights. We calculated the attributable risk fractions and population attributable risks, and used multinomial logistic Markov models and microsimulation to estimate the percentage of people ever diagnosed with asthma during working life.
\end{abstract}

Results The adjusted prevalence ratio comparing high-risk occupations with low-risk was 4.1 (95\% Cl 3.5 to 4.8$)$; the adjusted risk ratio was 2.6 (Cl 1.8 to 3.9 ). The attributable risk was $16.7 \%(\mathrm{Cl} 8.5$ to 23.6$)$; the population attributable risk was $11.3 \%$ (CI 5.0 to 17.2$)$. In microsimulations, $14.9 \%$ (CI 13.4 to 16.3 ) with low trigger exposure risk reported asthma at least once, ages 18-65, compared with $23.9 \%$ (CI 22.3 to 26.0 ) with high exposure risk.

Conclusion Adults were more than twice as likely to report a new asthma diagnosis if their occupation involved asthma triggers. Work exposures to asthma triggers may cause or aggravate about $11 \%$ of all adult asthma and increase the risk of work-life asthma by $60 \%$.

\section{INTRODUCTION}

About $7.7 \%$ of adults in the USA have asthma, ${ }^{1}$ costing more than $\$ 82$ billion annually. ${ }^{2}$ Researchers using data from 22 states in 2012 estimated that about $15.7 \%$ of asthma were caused or exacerbated by workplace asthma triggers (work-related asthma, WRA). ${ }^{3}$ The percentages of adult asthma that were work-related varied among states, ranging from $9.0 \%$ to $23.1 \%$. $^{3}$ Other researchers who reviewed the evidence in 2008 concluded that 10\%-15\% of adult asthma were attributable to occupational factors (occupational asthma), and that as much as $25 \%$ were WRA. ${ }^{4}$ Asthma triggers in the workplace include anhydrides, animal products, cereals, chloramine, dusts, dyes, enzymes, fluxes, formaldehyde,

\section{Key messages}

What is already known about this subject?

- People in certain occupations have a relatively high prevalence of asthma.

- However, there is limited nationally representative information about this risk in the USA, limited information about the incidence of work-related asthma generally or in population subgroups, and a lack of studies with extended follow-up.

\section{What are the new findings?}

- In results from up to 48 years of follow-up, people in high-risk occupations were more than four times as likely to report an asthma diagnosis than people in low-risk occupations, more than twice as likely to report being newly diagnosed, and $60 \%$ more likely to report an asthma diagnosis during working life (ages 18-65).

- Work exposures to asthma triggers may cause or aggravate about $11 \%$ of all adult asthma in the USA.

- Results suggested that about 1.8 million Americans had asthma that was attributable to occupational exposures.

\section{How might this impact on policy or clinical} practice in the foreseeable future?

- The results point to the importance of healthcare professionals asking patients about their occupational exposures, of public health education about workplace exposures, and of employers' actions to reduce those exposures, monitor workers for the development of asthma and limit exposures for those with asthma symptoms.

gums, latex, metals, pharmaceuticals and seafood. Certain occupations with exposures to such triggers have high asthma risks. Examples include agriculture, ${ }^{5}$ cleaning, ${ }^{5-7}$ entertainment, ${ }^{5} \quad 8-10$ healthcare, ${ }^{8} 10$ manufacturing, construction and wood-working, ${ }^{59}$ and protective services. ${ }^{5}$ WRA may be declining generally, ${ }^{911}$ but it is increasing in some occupations such as those with cleaning agent exposures. $^{6}$

About $8.9 \%$ of women and $5 \%$ of men in the USA have asthma. ${ }^{12}$ Women also have more WRA than men, ${ }^{3-9} 12$ although this may reflect different occupations. For example, women in healthcare occupations have elevated asthma risk, ${ }^{13-15}$ and women 
considerably outnumber men in healthcare. Among employed people, non-Hispanic African-Americans may have more asthma than non-Hispanic whites (hereafter white), although not necessarily WRA. Evidence of racial/ethnic variation in WRA is limited and mixed, and may be confounded by differences in occupational choice. ${ }^{38}$

Many WRA studies are limited to cross-sectional data, ${ }^{7}$ prevalence estimates, ${ }^{8}$ single occupations or selected occupation groups, ${ }^{10}$ small geographical areas, ${ }^{9}$ or countries with universal healthcare or well-established population registries, such as the UK. ${ }^{6}$ The studies reporting asthma incidence are typically limited to a single occupational group, ${ }^{16}$ have few participants in occupational groups, ${ }^{17}$ or use surveillance data that can be biased by reporting and data quality limitations, such as relying on voluntary reports from physicians or depending on individuals' healthcare access and use. ${ }^{18} 19$ In the USA several multistate asthma prevalence studies used data from the Behavioral Risk Factor Surveillance System (BRFSS) Asthma Call-back Survey (ACBS), with response rates typically 40\%-50\% and with 12-month follow-up. ${ }^{3820}$ The few WRA incidence studies typically have limited generalisability, such as a study of Norwegian smelters ${ }^{16}$ or studies of workers' compensation claims. ${ }^{9} 11$

We studied the association of working in occupations with relatively high risks of asthma trigger exposures with the prevalence, incidence and total work-life rates of WRA using nationally representative data with up to 48 years of follow-up, measuring occupation and physician-diagnosed asthma through age 65 . We hypothesised that people in occupations with relatively high asthma trigger exposures (hereafter 'high-risk occupations') would be more likely to have asthma than people in low-risk occupations. Our second hypothesis was that among people without asthma in a given year, those in high-risk occupations would be more likely than people in low-risk occupations to develop asthma. Third, we hypothesised that minorities and women would have more WRA than whites and men.

\section{METHODS}

\section{Data source and study sample}

We used data from the Panel Study of Income Dynamics (PSID). The PSID originated with 30000 families in the 1966-1967 national Survey of Economic Opportunity (SEO), conducted by the US Office of Economic Opportunity. Included household heads were younger than 60 years old and with income less than twice the poverty level. The original PSID, about 18000 people in 5000 households, was sampled from the SEO, with an additional national sample, together representing all ages and all income groups. The PSID interviewed participants annually from 1968 through 1997, then every 2 years. We used data from 1968 through 2015. The PSID maintains national representativeness by following children, ex-spouses and other adults of sampled households who form new households, and by adding additional samples as the population changes, such as Latinos in 1990 and immigrants in 1997.21 22 The survey was inperson through 1975, then by telephone; inperson survey continued for households without telephones. Response rates were 76\% and $88.5 \%$ in 1968 and 1969, respectively, and 96\%-98\% since then; item-specific non-response is less than $1 \% .^{22}{ }^{23}$ Modest attrition has not biased national estimates, including health measures. ${ }^{21}$ Participants reside in all 50 states.

As is common in population surveys, one person in each household, the 'reference person', provided asthma information for other family members. Although households may include other adults, the sample of reference persons and spouses/partners is weighted to represent the civilian adult population not living in institutions. Sampling weights account for selection probabilities and non-response, adjusted for age, sex, race/ethnicity, immigrant status, family income, region, urbanicity (metropolitan statistical area), education and employment status. The data are nationally representative except for Hispanic immigrants, who are under-represented. ${ }^{23}$

The inclusion criteria were age 18-65 at any time between 1968 and 2015; current and life history data on asthma provided at least once, 1999-2015; occupation information provided at least twice, 1968-2015; non-missing data for all study covariates; and a positive PSID sampling weight. The analytic sample included 13957 participants.

\section{Dependent variable: measuring asthma}

Every other year beginning in 1999, the PSID asked the following: if a doctor or other health professionals had ever diagnosed asthma and age of diagnosis; about asthma at each age from birth through 17; about the timing of diagnoses after age 17; and whether the participants 'still have it' or when it ended. We used these data to create a lifetime age-specific asthma history for each participant. The retrospective asthma record for all ages throughout life identified asthma incidence (new cases) and prevalence (new and existing cases) at each age.

\section{Identifying occupational status: exposure and reference groups}

With PSID occupation information collected in all waves, we constructed work-life occupational status records. The PSID measured occupation with codes from the Bureau of Census, using three-digit codes from the 1970 Census through 2001, then three-digit codes from the 2000 Census.

The exposure group reported occupations found to have high WRA risks in the studies cited above. We confirmed those risks for each occupational category using PSID data, estimating prevalence ratios and incidence risk ratios. High-risk occupations included occupations with animal or feather exposures; bulldozer operators; carpenters; cleaners and janitors; cooks and bartenders; entertainers and artists; metal filers, polishers and sanders; garden and farm workers; hair-stylists and nail salon workers; health aides and practical nurses; asbestos and insulation workers; mechanics and machinists; protective services; and welders (codes in online supplementary table 1). We also examined other high-risk occupations in previous research: millers (2000 Census code 501); miners (684); stone cutters, carvers and sanders (620 694865875892 963); sheet metal workers and tinsmiths (820); and textile workers (835). Finding no associations with asthma, we excluded those occupations from the high-risk category.

The reference group had low asthma trigger exposure risk (2000 Census codes in parentheses): inspectors, examiners, buyers, clerks, agents, directors, managers and supervisors (001-016, 023-056); underwriters, analysts, auditors and organisation officers (086-153); academic and related professionals (180-186); editors and writers (280-296); and other managers and clerical workers (500-593). Corresponding 1970 Census codes were 001-056, 086-096, 201-210 and 212-245. For the incidence analysis we used the principal reported occupation in each survey wave. For prevalence we used the occupation reported most often in the current and two preceding years. 


\section{Other measures}

The analytic data included a fixed variable indicating childhood atopy and a time-varying variable with atopy values for each year. We also used time-varying values for age, education, and current and past smoking. Variables indicated sex and whether observations represented non-Hispanic African-Americans (hereafter African-Americans), Hispanics, whites or other races/ethnicities.

\section{Analytic approach}

We estimated unadjusted and adjusted prevalence ratios and incidence risk ratios directly using log-binomial regression, ${ }^{24}$ accounting for the other measures just described, and for the survey design and sampling weights. For models that did not converge, we used Poisson analysis with robust variance, which provides similar results. We calculated the attributable risk fraction and the population attributable risk using indirect age standardisation with 5-year age intervals. The attributable risk fraction is the percentage of asthma that is caused or exacerbated by high-risk exposures among people with those exposures. ${ }^{25}$ Population attributable risk is the percentage of all asthma diagnoses in the USA that are caused or exacerbated by occupational exposures.

We also estimated the association of occupation with participants' reports of ever being diagnosed with asthma. Such estimates are typically higher than those for current asthma. For example, a Massachusetts study found a 13\% ever-diagnosed rate (11.1\% for men, $14.6 \%$ for women). ${ }^{26}$ Although such estimates are sometimes called 'lifetime' asthma, ${ }^{27}$ many people reporting ever-diagnosed asthma have not completed their work lives, so reports underestimate work-life asthma. Estimating work-life asthma required a completed work-life cohort, one in which all cohort members lived through age 65 . We simulated the cohort using the PSID data with a well-established multinomial logistic Markov chain regression model, estimated by maximum likelihood, and dynamic microsimulation. ${ }^{28-31}$ The model accommodates missing data and unmeasured asthma status transitions. ${ }^{28-31}$ We estimated asthma onset and recovery probabilities for each age, as well as the probabilities for remaining asthma-free or continuing with asthma, adjusted for sex, race/ethnicity, education, atopy and smoking. We used the probabilities to simulate populations of 100000 individuals, each with a known annual asthma status, ages 18-65. Bootstrapping provided CIs, calculated from the variation in results of 1000 simulated populations, each created with a random draw from the Markov model parameters. ${ }^{28-30}$ We analysed the data using SAS V.9.4.

\section{RESULTS}

\section{Sample characteristics}

Table 1 shows the sample characteristics. There were 13957 participants, averaging 14.7 years of follow-up (SD 11.7),

\begin{tabular}{|c|c|}
\hline Participants meeting the inclusion criteria, $\mathrm{n}$ & 13957 \\
\hline Years of follow-up, mean (SD) & $14.7(11.7)$ \\
\hline Person-years represented in the analysis & 205498 \\
\hline $\begin{array}{l}\text { Participants reporting any year in an asthma trigger occupation, } \\
\mathrm{n}(\%)\end{array}$ & $5906(42.3)$ \\
\hline Years in asthma trigger occupations, all participants, mean (SD) & $2.3(4.9)$ \\
\hline $\begin{array}{l}\text { Years in asthma trigger occupations, participants with } \geq 1 \text { year, } \\
\text { mean (SD) }\end{array}$ & $6.1(6.4)$ \\
\hline Ever reported an asthma diagnosis, ages $18-65, \%$ (SD) & $16.9(24.4)$ \\
\hline
\end{tabular}

\begin{tabular}{|c|c|c|}
\hline & $\begin{array}{l}\text { Unweighted } \\
\text { (SD) } \dagger\end{array}$ & $\begin{array}{l}\text { Weighted } \\
(95 \% \mathrm{Cl})\end{array}$ \\
\hline Age, first analytic observation, mean & $30.8(10.7)$ & 31.8 (31.5 to 32.1$)$ \\
\hline Age, last analytic observation, mean & $45.4(13.6)$ & 45.5 (45.1 to 45.8$)$ \\
\hline Female, \% & 53.4 & 49.1 (47.1 to 51.2 ) \\
\hline \multicolumn{3}{|l|}{ Race or ethnicity, \% } \\
\hline African-American or black & 32.0 & 10.5 (8.0 to 12.9$)$ \\
\hline Hispanic & 6.1 & 4.8 (3.5 to 6.1$)$ \\
\hline Non-Hispanic white & 58.7 & 80.9 (77.5 to 84.3$)$ \\
\hline Other race or ethnicity & 3.2 & $3.8(2.6$ to 5.0$)$ \\
\hline Educational attainment, mean years & $13.6(2.6)$ & 13.8 (13.7 to 13.9$)$ \\
\hline \multicolumn{3}{|l|}{ Smoking status, \% } \\
\hline Current smoker & 17.3 & 13.1 (9.4 to 16.7$)$ \\
\hline Past smoker & 31.9 & 32.1 (26.7 to 37.4$)$ \\
\hline Never smoker & 57.8 & 60.2 (54.9 to 65.5$)$ \\
\hline \multicolumn{3}{|l|}{ Atopy, \% } \\
\hline Childhood (ages 0 through 18) & 5.5 & $4.9(4.0$ to 5.8$)$ \\
\hline Adult & 3.0 & $2.9(1.5$ to 4.3$)$ \\
\hline
\end{tabular}

*Data source: Panel Study of Income Dynamics, 1968-2015; weighted results account for the survey design.

tSD shown for continuous variables.

205498 person-years, during which $42.3 \%$ reported working in a high-risk occupation at least once. Among those who ever worked in a high-risk occupation, the average number of years of exposure was 6.1 (SD 6.4).

Table 2 shows the unweighted and weighted descriptive results. The mean weighted baseline age was 31.8 years $(95 \% \mathrm{CI}$ 31.5 to 32.1 ). The PSID oversampled people with low income, which included African-Americans (32.0\% unweighted, 10.5\% weighted).

\section{WRA risks}

In results not shown in the table, at ages 25-34 the unadjusted rate of ever having asthma was $10.5 \%$ (CI 6.3 to 14.7 ) in lowrisk occupations and $21.2 \%$ (CI 7.2 to 35.2 ) in high-risk occupations. The average annual unadjusted incidence of asthma was 2.9/1000 (CI 2.0 to 3.7); the corresponding results were 2.1 (CI 1.3 to 2.8 ) in low-risk occupations and 6.2 (CI 2.7 to 9.8 ) in high-risk occupations.

The first column of table 3 shows the number of participants who ever reported working in each occupation (unweighted). For example, the relatively large number who ever reported working as cleaners or janitors $(n=4141)$ reflects the PSID's oversample of households with low income and the nearly five decades of follow-up. Table 3 also shows the results for prevalent and incident asthma. For example, cleaners or janitors had significantly higher risk of prevalent asthma than people in low-risk occupations (adjusted prevalence ratio 4.6, CI 1.8 to 11.6) and also higher risk of developing asthma in a given year (adjusted risk ratio 3.9 , CI 1.0 to 15.5 ).

The summary measure shown in table 3 reports the results for people in any high-risk occupation. Asthma was more common in high-risk occupations than in low-risk occupations (adjusted prevalence ratio 4.1, CI 3.5 to 4.8). Working in a high-risk occupation increased the adjusted risk of developing asthma by more than twofold (risk ratio 2.6, CI 1.8 to 3.9).

Table 4 shows the prevalence and risk ratios comparing lowrisk and high-risk occupations for specific populations. Highrisk occupations were associated with substantially more asthma in all groups. For example, among women the risk of developing 
Table 3 Asthma prevalence and incidence associated with workplace exposure to asthma triggers, USA *

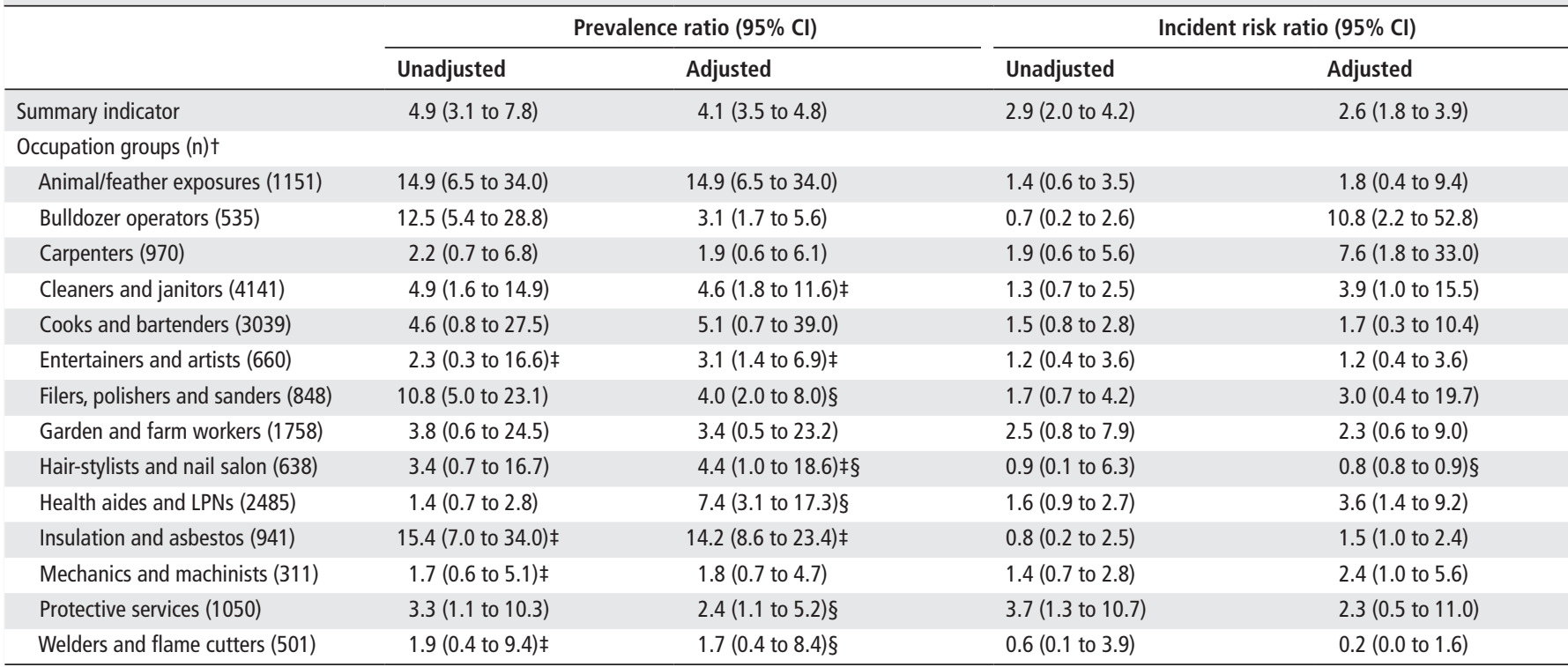

*Data source: Panel Study of Income Dynamics, 1968-2015; n=13 957; except as noted, results of log-binomial regression, adjusted for age, sex, race/ethnicity, education, atopy (childhood and current), current and past smoking status, survey design, and sampling weights.

$\mathrm{tn}$ is the number of participants ever reporting a given occupation (unweighted).

‡To obtain convergence, estimated with Poisson analysis with robust variance.

$\S$ Current atopy excluded to obtain convergence.

LPNs, licensed practical nurses.

asthma was more than four times greater in high-risk occupations than in low-risk occupations (risk ratio 4.1, CI 2.4 to 7.0); the comparable result for men showed a risk ratio of 2.4 (CI 1.5 to 3.7). Other comparisons were generally consistent with greater WRA risks for women and minorities than for men and whites.

Table 4 also shows the attributable risk fraction calculated with the summary indicator. Not shown is the attributable risk fraction for the entire population, which indicated that $16.7 \%$ (CI 8.5 to 23.6) of asthma in high-risk occupations were caused or exacerbated by occupational exposures. The corresponding population attributable risk indicated that $11.3 \%$ (CI 5.0 to 17.2) of all adult asthma were caused or exacerbated by exposures in high-risk occupations. The results suggest that women may have more WRA than men, and that African-Americans and Hispanics may have more WRA than whites. The attributable risk for women was $25.7 \%$ (CI 17.7 to 32.3 ), compared with $9.7 \%$ for men (CI $<0.1$ to 18.3 ). Hispanics were particularly likely to have asthma that was attributable to work in a high-risk occupation, with a population attributable risk of $23.8 \%$ (CI 4.4 to 39.3$)$.

\section{High-risk occupations and work-life asthma}

Table 5 shows the total work-life microsimulation results. All results show more ever-reported asthma in high-risk occupations than in low-risk occupations. For example, $23.9 \%$ (CI 22.3 to 26.0) of people in high-risk occupations reported an asthma diagnosis at least once during working life, compared with $14.9 \%$ (CI 13.4 to 16.3 ) in low-risk occupations. Thus, working in a high-risk occupation increased ever-reported asthma by $60 \%$. More than one-third (36.2\%, CI 30.4 to 39.9) of women in high-risk occupations reported an asthma diagnosis at some time during working life, as did a quarter of African-Americans (25.0\%, CI 22.7 to 26.7 ) and $28.5 \%$ of Hispanics (CI 24.9 to 31.8). The result for women is particularly notable given the corresponding rate for men: $11.5 \%$ (CI 10.3 to 12.7 ). These results suggest that women may experience a substantially high rate of WRA, although the result may be due to different occupations of women and men.

\section{DISCUSSION}

We studied the association of occupational asthma trigger exposures with WRA using nationally representative data with up to

Table 4 Prevalence ratios and incidence risk ratios for work-related asthma, comparing employment in occupations with high-risk asthma trigger exposures with employment in occupations with low-risk trigger exposures, with attributable risk and population attributable risk*

\begin{tabular}{lllll}
\hline & Prevalence ratio & Risk ratio & Attributable risk (\%) & $\begin{array}{l}\text { Population } \\
\text { attributable risk (\%) }\end{array}$ \\
\hline Women & $8.1(6.1$ to 10.7$)$ & $4.1(2.4$ to 7.0$)$ & $25.7(17.7$ to 32.3$)$ & $17.6(10.8$ to 23.9$)$ \\
\hline Men & $6.1(4.2$ to 8.8$)$ & $2.4(1.5$ to 3.7$)$ & $9.7(0.0$ to 18.3$)$ & $7.0(0.0$ to 14.4$)$ \\
African-American & $8.5(4.7$ to 15.6$)$ & $2.2(1.1$ to 4.2$)$ & $23.3(7.1$ to 34.7$)$ & $17.2(3.4$ to 29.0$)$ \\
\hline Hispanic & $8.2(1.5$ to 44.9$)$ & $6.8(2.1$ to 22.1$)$ & $33.7(11.3$ to 47.1$)$ & $23.8(4.4$ to 39.3$)$ \\
White & $5.3(3.1$ to 9.1$)$ & $2.6(1.5$ to 4.4$)$ & $15.3(0.0$ to 27.8$)$ & $10.1(0.0$ to 20.8) \\
\hline
\end{tabular}

*Data source: Panel Study of Income Dynamics, 1968-2015, weighted for national representation and accounting for the survey design; parentheses indicate lower and upper bounds of the $95 \% \mathrm{Cl}$; results of log-binomial regression accounting for age, sex, race/ethnicity, education, current and past atopy and smoking, survey design, and sampling weights. 
Table 5 Percentage of individuals who ever reported an asthma diagnosis in the USA, ages $18-65$, by workplace exposure to asthma triggers*

\begin{tabular}{lll}
\hline & \multicolumn{2}{l}{ Occupational risk of asthma trigger exposure } \\
\cline { 2 - 3 } & \multicolumn{1}{l}{ Low } & High \\
\hline All persons & $14.9(13.4-16.3)$ & $23.9(22.3-26.0)$ \\
Women & $26.0(23.9-29.2)$ & $36.2(30.4-39.9)$ \\
Men & $7.9(6.9-8.7)$ & $11.5(10.3-12.7)$ \\
\hline African-American & $15.9(14.3-17.9)$ & $25.0(22.7-26.7)$ \\
Hispanic & $18.4(16.3-20.9)$ & $28.5(24.9-31.8)$ \\
White & $14.1(13.0-15.0)$ & $22.2(20.0-23.9)$ \\
\hline
\end{tabular}

*Data source: Panel Study of Income Dynamics, 1968-2015; results from a completed cohort (all individuals followed from age 18 through age 65), from dynamic microsimulation.

48 years of follow-up. The results suggested that working in a high-risk occupation is common; $42.3 \%$ of participants reported doing so at least once. The duration of their exposures was notable, averaging about 6 years. Although some WRA can occur following extended exposures during latency periods lasting over 20 years, typically the WRA latent period with ongoing exposure is less than 2 years or slightly longer. ${ }^{4}$ Thus, many participants worked in high-risk occupations long enough to substantially increase their risk for WRA.

Consistent with our first hypothesis and previous estimates, 592027 people in high-risk occupations were more than four times as likely to report asthma diagnoses than people in low-risk occupations. Consistent with our second hypothesis, people in high-risk occupations were greater than two times more likely to have a new asthma diagnosis than those in lowrisk occupations. The results for individual occupational groups were generally consistent with that result, although there was considerable variation among the groups. In most instances the incidence risk ratios for specific occupational groups were not statistically significant at conventional levels, possibly due to a limited number of new asthma diagnoses in specific groups.

The unadjusted annual incidence of WRA was 2.9/1000. A previous asthma study in the USA, not limited to WRA, found an incidence of 3.8/1000 for adults in 2006-2008 (4.9/1000 for women vs 2.8/1000 for men). ${ }^{32}$ Studies of WRA incidence based on specialised samples ${ }^{16}$ or workers' compensation claims ${ }^{9} 11$ found similar results.

We also found that WRA may account for about $11.3 \%$ of all adult asthma, based on the population attributable risk. ${ }^{25}$ This standard epidemiological measure indicates the proportion of asthma in the population that is caused or exacerbated by occupational exposures. It therefore suggests the potential opportunity for reducing asthma through workplace interventions. ${ }^{4}$ The Centers for Disease Control and Prevention estimates that 7.7\% of adults in the USA had asthma in 2018, or about 15.6 million people. ${ }^{133}$ Applying the population attributable risk to this estimate suggests that about 1.8 million Americans had asthma that was caused or exacerbated by occupational exposures. However, if other exposures increase asthma risks in the home or the environment, and if such exposures are correlated with occupational choice, then the attributable risk may be overestimated. Similar reasoning applies to the population attributable risk. Our work life results showed significantly more ever-reported asthma in high-risk occupations (23.9\%) than in low-risk occupations (14.9\%). In high-risk occupations, $16.7 \%$ of asthma diagnoses were attributable to occupational exposures, consistent with the combined $16.3 \%$ result of longitudinal studies, ${ }^{34}$ and another estimate of $18.2 \%$ that included 'potential' occupational asthma along with confirmed cases. ${ }^{20}$

Our third hypothesis was that high-risk occupations would increase asthma risks of women more than those of men, ${ }^{7-9}$ and the risks of African-Americans and Hispanics more than those of whites. More than one-third of women in high-risk occupations reported an asthma diagnosis during working life, compared with about $11 \%$ of men. A quarter of African-Americans did so, $28.5 \%$ of Hispanics and 22\% of whites. The population attributable risks and the attributable risk percentages were also considerably greater for women and minorities than for men and whites. The observed differences between women and men, and also those associated with race/ethnicity, may have been confounded by occupation. This could occur if the high-risk occupations of women or minorities had higher risks than the high-risk occupations of men or non-minorities, or if women or minorities more commonly had high-risk occupations or remained in those occupations for longer periods. Bureau of Labor Statistics 2019 data $^{35}$ show that $92 \%$ of hair-stylists are women, $89 \%$ of health aides, $89 \%$ of housekeeping cleaners, $91 \%$ of practical nurses, $75 \%$ of non-farm animal caretakers and $86 \%$ of nail salon workers. Although men are more common in several other high-risk occupations, the results for women may be due in part to their high representation in these groups. The results for individual occupation groups did not suggest a clear pattern of extra risk in occupations that are more common for women (table 3). However, the individual high-risk occupations most common for women were among those with the largest samples, such as cleaners, health aides and practical nurses. This distribution of risk may have affected the results if women contributed disproportionately to the summary risk indicator.

The greater prevalence of asthma in high-risk occupations than in low-risk occupations was an expected outcome, given that high-risk and low-risk occupations were chosen based on evidence of asthma risk. What was not known prior to this study was the size of the extra asthma risks linked with occupations, whether differences between high-risk and low-risk occupations might be significant and meaningful when adjusted for confounders, the incidence of WRA, the association of high-risk occupations with total work-life ever-reported asthma, and the magnitude of asthma disparities affecting women and minorities.

\section{Limitations and strengths}

Recall bias may affect reports of asthma diagnoses. However, a study of the PSID illness histories concluded that they are generally valid. ${ }^{36}$ The onset age, duration or severity of childhood asthma may be associated with educational attainment, which may contribute to the range of occupations available to an individual as well as occupational choice. Asthma-related symptoms and sensitivities may also influence occupational choice independent of educational attainment. Thus, the results may be affected by childhood asthma selection effects.

We defined exposures by the participant's principal occupation. Americans increasingly work in multiple occupations at any given time. It would be useful to examine the impact of this phenomenon on WRA. Geographical confounders such as urban residence, air quality, housing characteristics and asthma triggers outside the workplace may have also contributed to the results.

Our analysis had several strengths. The PSID asked about asthma with questions and procedures that were similar to those of other national health surveys. However, few nationally representative data sets currently include information needed to estimate asthma incidence. ${ }^{32}$ PSID response rates and follow-up 
greatly exceed those of the BRFSS ACBS, ${ }^{23}$ limiting selection bias and increasing analytic power. Microsimulation allowed us to estimate ever-reported asthma for the entire typical adult working life. No previous study has provided such estimates.

The study spanned nearly five decades. Risks of asthma between and within occupations may have changed over time, affecting comparability with other studies. However, the long follow-up period was a study strength. It enabled us to calculate WRA incidence, which is rarely reported, particularly using nationally representative data.

\section{CONCLUSIONS AND IMPLICATIONS}

Occupations with high asthma trigger exposures were associated with more than double the risk of developing or exacerbating asthma, compared with working in a low-risk occupation. Work exposures to asthma triggers may cause or exacerbate about $11 \%$ of all adult asthma and about $17 \%$ of asthma among people in occupations with those exposures, and increase the risk of ever reporting asthma throughout working life by $60 \%$. More than one-third of women in high-risk occupations reported asthma during working life. The results point to the importance of clinicians asking patients about occupational exposures, of public health education about workplace exposures and of employers' actions to control asthma.

\section{Twitter Sarah B Laditka @SarahLaditka}

Acknowledgements We thank Cheryl Elman, PhD, an anonymous reviewer, and the editor for useful comments about this research.

Contributors JNL, SBL and AAA contributed to the conception and design of this study. All authors reviewed the research literature. JNL acquired the data. JNL and SBL analysed the data and drafted the first version of the manuscript. All authors contributed to the writing of the manuscript. All authors critically revised the manuscript and approved the final manuscript for publication.

Funding The authors have not declared a specific grant for this research from any funding agency in the public, commercial or not-for-profit sectors.

Competing interests None declared.

Patient consent for publication Not required.

Ethics approval The institutional review board (IRB) at our university determined that this research did not require IRB review.

Provenance and peer review Not commissioned; externally peer reviewed.

Data availability statement Data are available in a public, open access repository. The data used for this study are available from the Panel Study of Income Dynamics (http://psidonline.isr.umich.edu/default.aspx). The collection of data used in this study was partly supported by the National Institutes of Health under grant number R01 HD069609, and the National Science Foundation under award number 1157698

\section{ORCID iDs}

Sarah B Laditka http://orcid.org/0000-0003-2089-0787

Ahmed A Arif http://orcid.org/0000-0002-0237-9937

\section{REFERENCES}

1 Centers for Disease Control and Prevention. Data, statistics, and surveillance: asthma surveillance data. Available: https://www.cdc.gov/asthma/asthmadata.htm [Accessed 25 Jan 2020].

2 Nurmagambetov T, Kuwahara R, Garbe P. The economic burden of asthma in the United States, 2008-2013. Ann Am Thorac Soc 2018;15:348-56.

3 Centers for Disease Control and Prevention (CDC). Work-Related asthma-22 states, 2012. MMWR Morb mortal Wkly Rep 2015:64:343-6.

4 Tarlo SM, Balmes J, Balkissoon R, et al. Diagnosis and management of workrelated asthma: American College of chest physicians consensus statement. Chest 2008;134:1S-41.

5 Arif AA, Delclos GL, Whitehead LW, et al. Occupational exposures associated with work-related asthma and work-related wheezing among U.S. workers. Am J Ind Med 2003:44:368-76.

6 Carder M, Seed MJ, Money A, et al. Occupational and work-related respiratory disease attributed to cleaning products. Occup Environ Med 2019;76:530-6.
7 White GE, Seaman C, Filios MS, et al. Gender differences in work-related asthma: surveillance data from California, Massachusetts, Michigan, and new Jersey, 19932008. J Asthma 2014;51:691-702.

8 Dodd KE, Mazurek JM. Asthma among employed adults, by industry and occupation 21 states, 2013. MMWR Morb Mortal Wkly Rep 2016;65:1325-31.

9 LaSee C, Reeb-Whitaker C. Work-related asthma surveillance in Washington State: time trends, industry rates, and workers' compensation costs, 2002-2016. J Asthma 2019:1-10.

10 Arif AA, Delclos GL. Association between cleaning-related chemicals and work-related asthma and asthma symptoms among healthcare professionals. Occup Environ Med 2012:69:35-40.

11 Stocks SJ, McNamee R, van der Molen HF, et al. Trends in incidence of occupational asthma, contact dermatitis, noise-induced hearing loss, carpal tunnel syndrome and upper limb musculoskeletal disorders in European countries from 2000 to 2012. Occup Environ Med 2015;72:294-303.

12 Mazurek JM, Syamlal G. Prevalence of asthma, asthma attacks, and emergency department visits for asthma among working adults - National Health Interview Survey, 2011-2016. MMWR Morb Mortal Wkly Rep 2018;67:377-86.

13 Forastiere F, Balmes J, Scarinci M, et al. Occupation, asthma, and chronic respiratory symptoms in a community sample of older women. Am J Respir Crit Care Med 1998; 157:1864-70.

14 Dumas O, Donnay C, Heederik DJJ, et al. Occupational exposure to cleaning products and asthma in hospital workers. Occup Environ Med 2012;69:883-9.

15 Dumas O, Wiley AS, Quinot C, et al. Occupational exposure to disinfectants and asthma control in US nurses. Eur Respir J 2017;50:1700237.

16 Søyseth V, Johnsen HL, Henneberger PK, et al. The incidence of work-related asthmalike symptoms and dust exposure in Norwegian smelters. Am J Respir Crit Care Med 2012:185:1280-5.

17 Mirabelli MC, London SJ, Charles LE, et al. Occupation and three-year incidence of respiratory symptoms and lung function decline: the ARIC study. Respir Res 2012;13:24.

18 Walters Gl, Moore VC, McGrath EE, et al. Agents and trends in health care workers' occupational asthma. Occup Med 2013;63:513-6.

19 Bakerly ND, Moore VC, Vellore AD, et al. Fifteen-year trends in occupational asthma: data from the shield surveillance scheme. Occup Med 2008:58:169-74.

20 Mazurek JM, Knoeller GE, Moorman JE, et al. Occupational asthma incidence: findings from the behavioral risk factor surveillance system asthma call-back survey--United States, 2006-2009. J Asthma 2013;50:390-4.

21 Fitzgerald JM. Attrition in models of intergenerational links using the psiD with extensions to health and to sibling models. B E J Econom Anal Policy 2011;11.

22 Schoeni RF, Stafford F, McGonagle KA, et al. Response rates in national panel surveys. Ann Am Acad Pol Soc Sci 2013:645:60-87.

23 Johnson D, McGonagle K, Freedman V, et al. Fifty years of the panel study of income dynamics: past, present, and future. Ann Am Acad Pol Soc Sci 2018;680:9-28.

24 Spiegelman D, Hertzmark E. Easy SAS calculations for risk or prevalence ratios and differences. Am J Epidemiol 2005;162:199-200.

25 Levin ML. The occurrence of lung cancer in man. Acta Unio Int Contra Cancrum 1953:9:531-41.

26 Breton CV, Zhang Z, Hunt PR, et al. Characteristics of work related asthma: results from a population based survey. Occup Environ Med 2006;63:411-5.

27 Centers for Disease Control and Prevention. Lifetime asthma prevalence percents by age, United States: National health interview survey, 2017. Available: https://www. cdc.gov/asthma/nhis/2017/table2-1.htm [Accessed 16 Jun 2019].

28 Laditka JN, Laditka SB. Adverse childhood circumstances and functional status throughout adult life. J Aging Health 2018:30:1347-68.

29 Laditka JN, Laditka SB. Associations of multiple chronic health conditions with active life expectancy in the United States. Disabil Rehabil 2016;38:354-61.

30 Laditka SB, Laditka JN. An enduring health risk of childhood adversity: earlier, more severe, and longer lasting work disability in adult life. J Gerontol B Psychol Sci Soc Sci 2019;74:136-47.

31 Laditka SB, Wolf DA. New methods for analyzing active life expectancy. J Aging Health 1998; 10:214-41

32 Winer RA, Qin X, Harrington T, et al. Asthma incidence among children and adults: findings from the Behavioral Risk Factor Surveillance system asthma call-back survey-United States, 2006-2008. J Asthma 2012;49:16-22.

33 Census Bureau US, Division P. Annual estimates of the resident population for selected age groups by sex for the United States, states, counties and Puerto Rico Commonwealth and Municipios, 2019. Available: https://factfinder.census.gov/faces/ tableservices/jsf/pages/productview.xhtml?pid=PEP_2018_PEPAGESEX\&prodType $=$ table [Accessed 20 Jan 2020].

34 Torén K, Blanc PD. Asthma caused by occupational exposures is common - a systematic analysis of estimates of the population-attributable fraction. BMC Pulm Med 2009:9:7.

35 U.S.Bureau of Labor Statistics. Labor force statistics from the current population survey. household data, annual averages. table 11: employed persons by detailed occupation, sex, race, and Hispanic or Latino ethnicity, 2020. Available: https://www. bls.gov/cps/cpsaat11.htm [Accessed 5 Feb 2020]

36 Smith JP. Reconstructing childhood health histories. Demography 2009;46:387-403. 